\title{
Limitations of Continuous Neural Monitoring in Thyroid Surgery
}

\author{
Ettore Caruso, (1) Antonella Pino, (1) Alessandro Pontin, $(\mathbb{C}$ Giulia Pinto, $(\mathcal{C}$ Cristina Damiano, \\ (D) Antonina Catalfamo, (1) Fausto Famà, - Gianlorenzo Dionigi
}

Division for Endocrine Surgery, Department of Human Pathology in Adulthood and Childhood "G. Barresi", University Hospital G. Martino, University of Messina, Messina, Italy

\begin{abstract}
Continuous intraoperative neuromonitoring is currently the gold standard technique available to prevent recurrent laryngeal nerve injuries. It significantly reduces the complication rate compared with intermittent intraoperative neuromonitoring, and represents significant progress in thyroid surgery, particularly in cases of more difficult dissections.

There are, however, some technological and interpretative limits related to the lack of standardization of continuous intraoperative neuromonitoring and the prolonged length of time employed in the surgical positioning of the probe, despite various proposed approaches to the vagal nerve.

Nonetheless, this method can be considered a safe and modern approach to thyroid surgery that reduces post-surgical complications and provides useful information.

Keywords: Continuous neural monitoring; surgical complications; thyroid surgery.

Please cite this article as "Caruso E, Pino A, Pontin A, Pinto G, Damiano C, Catalfamo A, et al. Limitations of Continuous Neural Monitoring in Thyroid Surgery. Med Bull Sisli Etfal Hosp 2019;53(2):81-83".
\end{abstract}

$\mathrm{T}$ he first attempts at continuous monitoring (continuous intraoperative neuromonitoring, ClONM) of the recurrent laryngeal nerve (RLN) in thyroid surgery date back to the first half of the 1990s.

In 2007, the surgeon Wolfran Lamade, using an electrode placed on the vagal nerve (VN), performed the first cIONM. The same principle conceived by Lamade is still in use. ${ }^{[1-5]}$ By applying an electrode constantly in contact with VN and minimizing the interval between two stimulations (greater frequency), a real-time monitoring of the nerve and therefore of its function during the surgical procedure is ob- tained, thus overcoming the vulnerability of the intermittent intraoperative neuromonitoring (IONM) ${ }^{[6,7]}$

Various types of electrodes are available on the market, and they mainly differ in shape, size, flexibility, application method, and polarity. The electrodes are primarily distinguished on the basis of an open, closed, and semi-closed conformation. The open conformation may require the electrode to be placed on the surface of the nerve or to surround the nerve. In the former case, opening of the neuromuscular bundle and visualization of the surface of the nerve is required; in the latter case, a 360-degree dissection 
is required, followed by opening the neurovascular bundle and isolating and mobilizing VN. To achieve this, various types of surgical accesses can be used. The preferred one is median access with the incision of the linea alba cervicalis and divergence of the two layers of strip-muscles (superficially sternohyoid and deeply sternothyroid). Once the thyroid lobe is medialized, the neuromuscular bundle is visualized. The major limitations of this access are related to the glandular volume in case of a considerably increased thyroid size with predominantly lateral bulkiness or in case of recurrence because of the presence of the electrode on the operating field. Alternatively, the modified lateral access can be used. It is necessary to open the superficial cervical fascia between the sternohyoid muscle and the sternocleidomastoid muscle, directly reaching the neuromuscular bundle after separating the sternocleidomastoid muscle, thus allowing visualization even if the thyroid lobe is particularly bulky. VN occupies a middle and deep space between the internal jugular vein and the common carotid artery (73\%); however, it can also be found medially (15\%) or laterally $(8 \%)$ to the vessels and on the surface (4\%). ${ }^{[8]}$

Some studies have shown that clONM, compared with IONM, significantly reduces RLN injuries, representing a significant progress in thyroid surgery ${ }_{i}^{[1-5]} \mathrm{ClONM}$ is especially useful in difficult cases, such as recurrences with numerous adhesions, tumors infiltrating adjacent tissues, voluminous goiters, and Graves' disease. ${ }^{[9]}$

Nevertheless, cIONM has some limitations, both technological and interpretative. The first limitation is the time consumed in the surgical positioning of the cIONM probe, which is considered more difficult than other procedures with IONM or without monitoring. ${ }^{[6,7,9]}$ Various methods of approaching $\mathrm{VN}$ have been proposed, and several probes are available on the market that help simplify the procedure. ${ }^{[10]}$ Prototypes of transcutaneous or percutaneous cIONM models have proved to be significantly feasible and appear to be the same as the standard cIONM. Use of such prototypes could make the procedure simple and safer.

In 2012, Friedrich et al. conducted a prospective randomized study on the safety of cIONM and did not detect any hemodynamic alterations or reductions in plasma cytokine or tumor necrosis factor-alpha levels despite an increase in vagal tone.

Another possible limitation of cIONM could be linked to the lack of standardization of its use. Significant differences in the criteria used for the "alarm" threshold ${ }^{[11-13]}$ have been reported in the literature. For an alarm to be high, the following combined criteria must be present: (a) loss of amplitude $>50 \%$; (b) increase in latency $>10 \%$; (c) number of combined records; (d) associated high risk of surgical maneuver; (e) exclusion of systemic, anesthetic, and technical factors. ${ }^{[14-16]}$ All of these are important criteria that must be met to minimize the rate of false positives and false negatives. In this regard, it is clear that establishing uniformity criteria for alarm levels is essential. Furthermore, if low threshold were used to raise an alarm, the number of false positives would increase, with surgical procedures unnecessarily altered or interrupted. Conversely, if high threshold were used to raise an alarm, the possibility of false negatives and therefore of RLN lesions would increase. It is evident that further studies are needed to define more appropriate parameters for better interpretation of a decrease in response.

Despite the increasing number of centers and surgeons using this procedure, no standard method has been established; thus, a discussion has recently been opened on the safety of cIONM. ${ }^{[17,18]}$

Considering the well-known advantages of cIONM, adequate training remains the gold standard for performing a safe procedure with cIONM. No data are yet available on the cIONM learning curve, on the technique to be used (configuration and correct use of the cIONM equipment), or on surgeon's interpretation. ${ }^{[19]}$

In conclusion, we can affirm that despite cIONM being an excellent tool for surgeons in thyroid surgery to prevent inadequate maneuvers, RLN lesions may occur. Therefore, the surgeons must know that RLN paralysis can occur even with the use of cIONM. CIONM allows to recognize and modify the surgical action in case of non-acute dilation stress of RLN (such as traction, compression), whereas in case of rapid and sudden damage (such as thermal lesions, section), the surgical maneuver cannot be changed. Being a recently evolving technique, cIONM is subject to studies that aim to improve its functionality, implement its interpretation, and minimize technical errors. This method is not only safe but also confers protection to the patient, reducing postoperative complications and providing useful information for a novel approach to thyroid surgery.

\section{Disclosures}

Peer-review: Externally peer-reviewed.

Conflict of Interest: None declared.

Authorship Contributions: Concept - G.D.; Design - G.D., E.C.; Supervision - G.D.; Materials - E.C., P.A., P.A., P.G., C.D., A.C., F.F., G.D.; Data collection \&/or processing - E.C., P.A., P.A., P.G., C.D., A.C., F.F., G.D.; Analysis and/or interpretation - E.C., P.A., P.A., P.G., C.D., A.C., F.F., G.D.; Literature search - E.C.; Writing - G.D., E.C., F.F.; Critical review - E.C., P.A., P.A., P.G., C.D., A.C., F.F., G.D. 


\section{References}

1. Lamadé W, Meyding-Lamadé U, Hund E, Senninger N, Herfarth C. Transtracheal monitoring of the recurrent laryngeal nerve. Prototype of a new tube. [Article in German]. Chirurg 1997;68:193-5.

2. Lamadé W, Brandner R, Brauer M, Hund E, Klar E, Herfarth C. Continuous monitoring of the recurrent laryngeal nerve. [Article in German]. Langenbecks Arch Chir Suppl Kongressbd 1998;115:1055-7. [CrossRef]

3. Lamadé W, Meyding-Lamadé U, Buchhold C, Brauer M, Brandner $\mathrm{R}$, Uttenweiler $\mathrm{V}$, et al. First continuous nerve monitoring in thyroid gland surgery. [Article in German]. Chirurg 2000;71:551-7.

4. Lamadé W, Ulmer C, Seimer A, Molnar V, Meyding-Lamadé U, Thon $\mathrm{KP}$, et al. A new system for continuous recurrent laryngeal nerve monitoring. Minim Invasive Ther Allied Technol 2007;16:149-54.

5. Ulmer C, Koch KP, Seimer A, Molnar V, Meyding-Lamadé U, Thon $\mathrm{KP}$, et al. Real-time monitoring of the recurrent laryngeal nerve: an observational clinical trial. Surgery 2008;143:359-65. [CrossRef]

6. Schneider R, Randolph GW, Sekulla C, Phelan E, Thanh PN, Bucher $M$, et al. Continuous intraoperative vagus nerve stimulation for identification of imminent recurrent laryngeal nerve injury. Head Neck 2013;35:1591-8. [CrossRef]

7. Schneider R, Bures C, Lorenz K, Dralle H, Freissmuth M, Hermann $M$. Evolution of nerve injury with unexpected EMG signal recovery in thyroid surgery using continuous intraoperative neuromonitoring. World J Surg 2013;37:364-8. [CrossRef]

8. Dionigi G, Chiang FY, Rausei S, Wu CW, Boni L, Lee KW, et al. Surgical anatomy and neurophysiology of the vagus nerve (VN) for standardised intraoperative neuromonitoring (IONM) of the inferior laryngeal nerve (ILN) during thyroidectomy. Langenbecks Arch Surg 2010;395:893-9. [CrossRef]

9. Zhou L, Dionigi G, Pontin A, Pino A, Caruso E, Wu CW, et al. How does neural monitoring help during thyroid sugery for Graves' disease? J Clin Transl Endocrinol 2018;15:6-11. [CrossRef]

10. Monticelli G. L'elettroneurostimolazione: neurofisiologia ed appli- cazione dei moderni stimolatori. 2003.

11. Chávez KV, Ramírez J, Pantoja JP, Sierra M, Velázquez-Fernández D, Herrera MF. Continuous intraoperative neural monitoring in thyroid surgery: a Mexican experience. Updates Surg 2017;69:505-8.

12. Marin Arteaga A, Peloni G, Leuchter I, Bedat B, Karenovics W, Triponez F, et al. Modification of the Surgical Strategy for the Dissection of the Recurrent Laryngeal NerveUsing Continuous Intraoperative Nerve Monitoring. World J Surg 2018;42:444-50. [CrossRef]

13. Brauckhoff K, Vik R, Sandvik L, Heimdal JH, Aas T, Biermann M, et al. Impact of EMG Changes in Continuous Vagal Nerve Monitoring in High-Risk Endocrine Neck Surgery. World J Surg 2016;40:672-80.

14. Schneider R, Sekulla C, Machens A, Lorenz K, Nguyen Thanh P, Dralle $\mathrm{H}$. Postoperative vocal fold palsy in patients undergoing thyroid surgery with continuous or intermittent nerve monitoring. Br J Surg 2015;102:1380-7. [CrossRef]

15. Phelan E, Schneider R, Lorenz K, Dralle H, Kamani D, Potenza A, et al. Continuous vagal IONM prevents recurrent laryngeal nerve paralysis by revealing initial EMG changes of impending neuropraxic injury: a prospective, multicenter study. Laryngoscope 2014;124:1498-505. [CrossRef]

16. Mangano A, Kim HY, Wu CW, Rausei S, Hui S, Xiaoli L, et al. Continuous intraoperative neuromonitoring in thyroid surgery: Safety analysis of 400 consecutive electrode probe placements with standardized procedures. Head Neck 2016;38 Suppl 1:E1568-74.

17. Almquist $M$, Thier $M$, Salem F. Cardiac arrest with vagal stimulation during intraoperative nerve monitoring. Head Neck 2016;38:E2419-20. [CrossRef]

18. Terris DJ, Chaung K, Duke WS. Continuous Vagal Nerve Monitoring is Dangerous and Should not Routinely be Done During Thyroid Surgery. World J Surg 2015;39:2471-6. [CrossRef]

19. Suh I, Yingling C, Randolph GW, Duh QY. A Novel Method of Neuromonitoring in Thyroidectomy and Parathyroidectomy Using Transcutaneous Intraoperative Vagal Stimulation. JAMA Surg 2016;151:290-2. [CrossRef] 